\title{
Calidad de vida, sintomatología de ansiedad y depresión en personas con VIH: el papel del psicólogo de la salud
}
Quality of life, symptoms of anxiety and depression in people with HIV: the role of health psychologist

María, A. Canales-Zavala ${ }^{a}$, Andrea V. Hernández-Ruiz ${ }^{a}$, Stephany González-Venegas ${ }^{a}$, Alejandra C. Monroy-Avalos ${ }^{a}$, Arlet A. Velázquez-Camarillo ${ }^{a}$, M. Leticia Bautista-Díaz ${ }^{b}$

\begin{abstract}
:
The Human Immunodeficiency Virus (HIV), in addition to being a global public health problem, is also a national one, due to the current high incidence rates (105, 170 Mexican men and women), this disease not only affects serious biological dimension but also the social and psychological, the latter dimension can worsen the health condition of the person who gets infected with the virus. Therefore, the objective of this essay was to review the role of the health psychologist in the quality of life, in the symptoms of anxiety and/or depression in people with HIV. The interaction among the symptoms produced by HIV with the symptoms of anxiety and depression makes adherence to the treatment of HIV-positive people more complex and this in turn deteriorates the quality of life. Because of the risk factors for contracting the virus on greater extent are behavioural, for example, unprotected sex, use of unsterilized or reused syringes, among others, the role of the health psychologist becomes a cardinal part in health promotion and disease prevention, therefore, this health professional must be a mandatory part of the interdisciplinary care and treatment team in this population.
\end{abstract}

Keywords:

HIV, Depression, Quality of life, Anxiety, Psychology

\section{Resumen:}

El Virus de Inmunodeficiencia Humana (VIH) además de ser un problema de salud pública mundial, también lo es a nivel nacional, debido a los altos índices de incidencia actuales (105, 170 hombres y mujeres mexicanos), esta enfermedad no sólo afecta de manera grave la dimensión biológica sino también la social y la psicológica, esta última puede empeorar la condición de salud de quien lo contrae. Por tanto, el objetivo del presente ensayo fue revisar el papel del psicólogo de la salud en la calidad de vida, en la sintomatología de ansiedad y de depresión en personas con VIH. La interacción entre los síntomas producidos por el VIH con la sintomatología de ansiedad y de depresión hace más compleja la adherencia al tratamiento de las personas seropositivas y a su vez deterioran la calidad de vida. Así, debido a que los factores de riesgo para contraer el virus en mayor medida son conductuales, por ejemplo, relaciones sexuales sin protección, uso de jeringas no esterilizadas o reutilizadas, entre otros, el papel del psicólogo de la salud se vuelve parte cardinal en la promoción de la salud y la prevención de la enfermedad, por ello, este profesional de la salud debe formar parte obligatoria del equipo interdisciplinario de atención y tratamiento en esta población.

Palabras Clave:

VIH, Depresión, Calidad de vida, Ansiedad, Psicología

\section{Introducción}

El Virus de Inmunodeficiencia Humana $(\mathrm{VIH})$ es un retrovirus que afecta el sistema inmunitario, dicho sistema se encarga de proteger al ser humano de contraer enfermedades, pero al ser atacado este sistema, se vuelve blanco de diversas enfermedades ocasionadas por bacterias o por otros virus (1).
El VIH además de afectar gravemente la dimensión física también altera la dimensión social y psicológica de quien lo contrae. En cuanto a la dimensión psicológica, se encuentran diversas alteraciones como los cambios de ánimo, de pensamientos y de conducta, así como una serie de mitos, tabúes y prejuicios que impactan negativamente la vida de quienes viven con dicha condición, que de no atenderse adecuada y oportunamente podrían desencadenar alteraciones más

${ }^{a}$ Estudiantes del $8^{\circ}$ semestre de la Licenciatura en Psicología, Instituto de Ciencias de la Salud, Universidad Autónoma del Estado de Hidalgo; María A. Canales-Zavala, Email: abycanalez60497@gmail.com; Andrea V. Hernández-Ruiz, Email: avanessahruiz@gmail.com; Stephany González-Venegas, Email:Stephany.venegas92@gmail.com; Alejandra C. Monroy-Avalos, Email: alechinita1695@gmail.com; Arlet A. Velázquez-Camarillo, Email: ailinvelazquezcamarillo@gmail.com

${ }^{\mathrm{b}}$ Autor de Correspondencia: Profesora de la Licenciatura en Psicología, Facultad de Estudios Superiores Iztacala, Universidad Nacional Autónoma de México, ORCID: 0000-0003-1154-1737, Email: psilety7@ gmail.com 
complejas como la presencia de sintomatología de depresión, de ansiedad y una calidad de vida deteriorada, por mencionar algunas. De manera resumida, la labor del psicólogo de la salud en las personas con $\mathrm{VIH}$ es incidir en la prevención primaria, secundaria y terciaria.

El Centro Nacional para la Prevención y el Control del VIH y el Sida (CENSIDA) (2) refiere que a nivel nacional hay 182 mil casos de VIH y 105. 170 de SIDA (enfermedad infecciosa causada por el virus de VIH), de los cuales, en cuanto a sexo $83.1 \%$ son hombres y $16.9 \%$ son mujeres. De la población femenina $82 \%$ ha contraído el virus a través de relaciones heterosexuales, mientras que $57.6 \%$ de los varones lo han contraído por relaciones homosexuales, pero se destaca que en ambos casos la principal causa fue la ausencia de protección, de este modo, la esfera conductual juega un papel importante en la prevención del $\mathrm{VIH}$, la cual se puede promover con talleres psicoeducativos 0 intervenciones psicológica.

En cuanto a lo social, el papel de la salud, es dar pie a la sensibilización de la sociedad que critica, ofende y/o discrimina a quienes viven con $\mathrm{VIH}$.

Otra labor fundamental del psicólogo de la salud es prevenir dificultades en el transcurso del virus, como lo es aminorar el impacto psicológico en los portadores, es decir, dotar de herramientas para encarar un diagnóstico seropositivo, surgiendo así un curso de acción dirigido a generar conductas positivas y saludables para los afectados y para la comunidad (3). Uno de los principales propósitos -en términos de bienestar-, es lograr que el paciente sea resiliente (capacidad de los seres humanos para adaptarse positivamente a situaciones adversas) ante la situación que está viviendo, al respecto es necesario considerar que no todos los pacientes poseen los mismos recursos-para enfrentarse al diagnóstico, por lo que parte del trabajo es brindar acompañamiento para hacer este proceso más llevadero, además, informar acerca de los beneficios de seguir un tratamiento antirretroviral y de tomar una terapia psicológica para así, generar factores de protección dirigidos a evitar el desarrollo de conflictos emocionales, cognitivos y conductuales.

Con relación a la adherencia al tratamiento de las personas con $\mathrm{VIH}$, es necesario que éstas conozcan del perjuicio de no llevarlo a cabo. Si los pacientes fortalecen su sistema inmunitario,-entonces serán capaces en mayor medida de afrontar cualquier enfermedad o infección. Al respecto, la familia tiene un papel determinante como factor de protección, ya que, su apoyo impacta positivamente a la adherencia al tratamiento, lo cual contribuye a un pronóstico favorable (4).

Generalmente, obtener un diagnóstico seropositivo, propicia el desarrollo de síntomas de depresión y/o de ansiedad, porque es tal la desinformación en torno al $\mathrm{VIH}$, que lo primero que se piensa es "muerte" lo que también afecta el sistema inmune. Posterior al diagnóstico, la adaptabilidad de ser portador del virus dependerá de muchos factores externos e internos, como género, estatus social, apoyo de sus círculos sociales, educación, creencias religiosas, personalidad, inteligencia, estilos de afrontamiento, control emocional, entre muchos más. De acuerdo con Pérez (5) todos estos factores pueden ser modificados en el proceso, lo cual tiene que ver con la conducta individual proporcionando un campo de acción para los psicólogos de la salud al poder intervenir en el proceso adaptativo y de reestructuración, que no solo se limita a entrar en juego cuando ya está presente el diagnóstico, sino en la prevención de conductas de riesgo y promoción de factores de protección, además de un estado óptimo de salud. Así, es relevante su abordaje desde la psicología de la salud, por ello, el objetivo del presente ensayo fue revisar el papel del psicólogo de la salud en la calidad de vida, en la sintomatología de ansiedad y de depresión en personas con $\mathrm{VIH}$.

\section{VIH \\ Definición}

El Virus de Inmunodeficiencia Humana (VIH) tiene origen en la familia retroviridae, ligado a los lentivirus y correspondiente a los virus Ácido Ribonucleico (ARN) ; debido a su origen y a su capacidad por sus enzimas de transcriptasa inversa puede condensar el ADN a partir del ARN viral, posee tres capas, la capa interna o nucleoide, la capa icosaédrica conformada de p24 y la capa externa o envoltura, añadiendo sus genes reguladores que efectúan el proceso de síntesis de las proteínas reguladoras fundamentales en el proceso de replicación viral (1). Cuando este virus ataca y agrede el sistema inmunológico de las personas casi por completo de su función, dejándolo vulnerable, sin la capacidad de proteger y luchar contra infecciones y enfermedades (6).

\section{Datos epidemiológicos del VIH}

Los datos epidemiológicos se pueden identificar en tres alcances, los mundiales, los nacionales y los estatales. A continuación se describen de manera general.

Mundiales: El Factográfico de la Salud (7) informa que a nivel mundial, 36.7 millones de personas que se contagiaron del virus en el 2016, sólo 21.7 millones son tratadas. Para 2017 se registraron 1.8 millones de casos nuevos. Pero se puntualiza que en el 2016, hubo una disminución del $11 \%$ en los decesos en estos pacientes.

Nacionales: Según el Centro Nacional para la Prevención y el Control del VIH y el SIDA (8) en México, la población más afectada son los hombres que tienen relaciones homosexuales, trabajadores sexuales, usuarios de drogas, así como personas transgénero, travestis y transexuales; para el 2014 existían en México 190 mil personas infectadas por el virus y para el 2015 se notificaron 235, 953 casos, en cuanto a edad, $33.9 \%$ son jóvenes de entre 15 y 29 años, respecto al sexo $19.8 \%$ son mujeres y el $80.2 \%$ son hombres, de estos 
porcentajes el $95.3 \%$ de los casos adquirieron el virus por contacto sexual sin protección; y las entidades donde se encuentra la mayor tasa de casos es en la Ciudad de México con 422, Yucatán con 317, Campeche con 301, Quintana Roo con 295 y Veracruz con 285.

Estatales: Según la Secretaría de Salud de Hidalgo (9) en 2014 se registraron 439 casos de VIH de los cuales 237 corresponde a la ciudad de Pachuca; 90 de Mineral de la Reforma-26 de Actopan; 20 de Apan; 15 de Atotonilco de Tula; 14 de Tlahuelilpan; 12 de Progreso de Obregón; 9 de Epazoyucan; 9 Zapotlán de Juárez y 7 de Singuilucan.

Elizondo en 2018 (10) señaló que con base en los datos del Comité Estatal de Prevención de VIH, la mayoría de los contagios fueron por vía sexual con predominio en los hombres.

\section{Causas}

El Programa de las Naciones Unidas sobre el VIH/SIDAMinisterio de la Protección Social (11), existen tres vías principales de contagio del VIH que en la mayoría son conductuales: diversas parejas sexuales, no usar condón, el sexo comercial, la práctica de penetración oral, anal, relaciones homosexuales y el inicio temprano de relaciones sexuales sin protección.

2) otra vía de transmisión es la sanguínea, esto sucede cuando las personas reciben transfusión de sangre contaminada; se estima que $95 \%$ de personas que han recibido una unidad de sangre contaminada tiene mayor riesgo de contraer el $\mathrm{VIH}$, de igual manera, cuando el proceso industrial de la eliminación de agentes virales no se lleva a cabo correctamente puede generarse un contagio.

3) el uso de jeringas contaminada en-drogodependientes-con psicoestimulantes, esto debido a que muestran más conductas de riesgo, como agresión, aumento de la actividad sexual, reutilización de jeringas, uso de agujas no esterilizadas o reutilizadas de la prácticas de acupuntura (12). También en aquellas personas que se realiza algún tatuaje o perforaciones, sin los debidos cuidados sanitarios, así como en el manejo accidental con agujas u otro tipo de material punzo cortante contaminado con sangre de personas seropositivas (13). Una población vulnerable para el contagio de $\mathrm{VIH}$, son los pacientes con hemofilia ya que pueden contaminarse por vía sanguínea, esto debido a las transfusiones de sangre que requieren constantemente (14).

Otra vía de contagio es la transmisión vertical, que se da entre la madre seropositiva y el feto (durante el embarazo), mismo que se desarrolla en los primeros meses de gestación, o a través del parto, debido a que el virus se localiza en las secreciones y en la sangre que el producto aspira o deglute al salir del conducto vaginal. Por último, la transmisión se puede dar por medio de la lactancia donde el virus se encurta libre en la leche materna y en los calostros (15).

\section{Consecuencias}

Resulta inevitable mencionar la serie de consecuencias que trae consigo el VIH, desafortunadamente, quien vive con este virus presenta alteraciones biológicas, psicológicas y sociales. En cuanto a las biológicas, Lamotte (16) refiere que algunos aparatos y sistemas que son afectados son: el respiratorio, el digestivo y el sistema nervioso central (SNC), los cuales al ser dañados producen diversas enfermedades graves como la neumonía, la tuberculosis pulmonar, la sinusitis, la enteropatía y la disfagia, entre otras muchas más. Por otra parte, si el VIH se complica, podrían aparecer otras enfermedades, por ejemplo: herpes zóster, multidermatoma, candidiasis bucal, dermatitis seborreica e hiperpigmentación cutánea, trombocitopenia, entre otras.

Los antirretrovirales presentan efectos secundarios, entre ellos se muestran las alteraciones morfológicas, como la lipoatrofia que se caracteriza por alteraciones en la figura corporal, resultado de la pérdida de grasa, en la que mayormente se ven afectados los brazos, las piernas, los glúteos y la cara; en contraste está la lipohipertrofia, caracterizada por una acumulación progresiva de grasa periférica y central, ésta se visualiza en los cambios que se dan en el crecimiento abdominal, crecimiento de las mamas y en la aparición de joroba (17).

En cuanto a lo psicológico y lo social, el ser humano es más que el cuerpo que posee, por lo cual, es importante hacer referencia a la dualidad mente-cuerpo, ya que si se considera que como individuos se poseen emociones y afectos se podrán tomar en cuenta las consecuencias psicológicas que el VIH trae consigo. Piña y Robles (18) afirman que la mayoría de portadores presentan alteraciones emocionales, algunas de ellas son: la pérdida de autoestima, aislamiento, pérdida de la pareja, pérdida de empleo, culpabilidad por conductas de riesgo, incertidumbre frente al futuro, frustración, síntomas de depresión, de ansiedad, y de manera general se afecta su calidad de vida. EI VIH daña parte de las áreas cognitivas, entre ellas se encuentran: la atención, la memoria de trabajo, la velocidad de procesamiento, las funciones ejecutivas y las habilidades motoras, así las consecuencias se encuentran interconectadas afectando las tres esferas del ser humano, la biológica, la social y la psicológica (13).

\section{Diagnóstico}

Para la detección del retrovirus humano se utiliza una serie de pruebas de laboratorio, estas se catalogan en: directas 0 indirectas. Las primeras son aquellas que facilitan el diagnóstico precoz de la infección y que permiten el rastreo de los componentes (proteínas y ácido nucleico) que el virus contiene, anticipándose a la respuesta inmunológica que puede desarrollar el cuerpo a consecuencia. Dichas pruebas tienen el inconveniente de ser muy costosas, entre estas se encuentran la antigenemia $P 24$, cultivo viral y reacción de cadena de la 
polimerasa. Mientras que, las pruebas indirectas son las que demuestran una respuesta inmune por parte del huésped, están basadas en estudios serológicos para la detección de anticuerpos en el suero y son menos costosas que las directas (19).

\section{Tratamiento}

Aunque, no existe una cura para el VIH, el seguimiento estricto de la terapia antirretroviral puede disminuir significativamente el progreso de la enfermedad, además de evitar infecciones y complicaciones secundarias (20), por tanto, alarga la esperanza de vida de manera más sana (9). La adherencia al tratamiento puede reducir el riesgo de la transmisión del virus.

El tratamiento antirretroviral (TAR) se recomienda para las personas con la condición seropositiva, ya que esto ayudará a que disminuyan los efectos que conlleva la enfermedad. Las personas que reciben TAR, ingieren una combinación de medicamentos contra el $\mathrm{VIH}$ todos los días. Por lo general, el régimen de tratamiento inicial de dicha infección incluye tres o más medicamentos de por lo menos dos clases diferentes, por lo que puede resultar complejo económicamente y conductualmente (9).

Si se considera a la salud como el estado de completo bienestar físico, mental y social, y no solamente como la ausencia de afecciones o enfermedad, como lo establece la Organización Mundial de la Salud, el tratamiento de las personas con VIH debe darse en un marco de salud integral, incluyendo no sólo el tratamiento médico sino un adecuado soporte psicológico y social. Por lo que, es imperante. La realización de intervenciones interdisciplinarias como lo es la psicología de la Salud, al comprender y tratar la sintomatología de depresión, de ansiedad y la mala calidad de vida contribuyen al proceso negativo de la enfermedad en las personas con $\mathrm{VIH}$ (21).

\section{CALIDAD DE VIDA}

\section{Antecedentes}

Calidad de Vida (CV) es un concepto que emerge desde mediados del siglo pasado principalmente, del punto de vista sociológico, seguido del médico y más recientemente, evolucionó a tomar en cuenta lo psicológico, incluyendo temas como felicidad y bienestar (22). El concepto de CV posterior a la época de la Segunda Guerra Mundial se operacionalizó por poseer estabilidad financiera, información recaba de datos socioeconómicos, de nivel educativo, calidad de la vivienda, además de otros indicadores materiales (23).

Moreno y Ximénez (24) sostienen que el concepto de $\mathrm{CV}$, no debe concretarse a lo material y que debe tomarse en cuenta indicadores subjetivos como la salud física y psicológica, es decir, el bienestar en general. Al respecto Nava (25) sostiene que los constituyentes de CV deben ser objetivos y subjetivos, entendiendo por los primeros: relaciones armónicas con el ambiente y comunidad, salud objetiva y bienestar material; por los segundos: expresión emocional, intimidad, productividad personal, seguridad y salud física y psicológica percibida.

\section{Definición}

Debido a la complejidad del término $\mathrm{CV}$, es difícil contar con una definición universal y completa, por lo que es adecuado considerar la de la OMS (1995), que indica que es la percepción que posee cada individuo dentro de un contexto (sistema cultural y de valores) en que se vive y con relación a sus objetivos, esperanzas, normas y preocupaciones. En esta definición queda implícito que la CV considera al ser humano como un ente bio-psicosocial, e incluye la salud física, psicológica, relaciones sociales, espiritualidad y el medio ambiente (26).

De este modo, la CV es un concepto multidimensional que comprende aspectos físicos, psicológicos y sociales, las percepciones de la salud intervienen en cada de esas dimensiones, debido a lo que se percibe del estado de salud, y al análisis objetivo del mismo, no todos las personas experimentan la misma sensación de bienestar bajo las mismas circunstancias, es decir, no todos tienen la misma CV, es por ello que al cúmulo de sensaciones y percepciones personales de $<<$ sentirse bien >> más la sensación de bienestar en cada sujeto forman lo que es la CV (27).

\section{Dimensiones}

Aun considerando la definición de CV de la OMS, se ha sugerido que una de las ventajas de utilizar dimensiones es la objetividad y comparabilidad, ya que representan un lenguaje común que facilita una medida estandarizada. Estas son herramientas útiles porque permiten valorar diferentes magnitudes como, por ejemplo, el grado de cumplimiento de un objetivo o el grado de satisfacción de un participante en la formación. De esta manera, existen las dimensiones para medir la CV de los individuos ayudando a que sea lo más objetivo posible (28).

Schalock y Verdugo (29) sugieren ocho dimensiones centrales de CV siguientes:

Bienestar: Hace referencia a sentirse tranquilo, seguro sin agobios no estar nervioso. Se evalúa mediante los indicadores: satisfacción, autoconcepto y ausencia de estrés o sentimientos negativos.

Relaciones Interpersonales: Relacionarse con distintas personas, tener amigos y llevarse bien con la gente (vecinos, compañeros, etc.) Se mide con los siguientes indicadores: relaciones sociales, tener amigos claramente identificados, relaciones familiares, contactos positivos y gratificantes, relaciones de pareja y sexualidad.

Bienestar Material: Tener dinero suficiente para comprar lo que se necesita y desea tener, contar con una vivienda y lugar de trabajo adecuados. Los indicadores evaluados son: vivienda, lugar de trabajo, salario (pensión, ingresos), posesiones (bienes 
materiales), ahorros (o posibilidad de acceder a caprichos).

Desarrollo Personal: Se refiere a la posibilidad de poder aprender distintas cosas, tener conocimientos y realizarse personalmente. Se mide con los indicadores: limitaciones/capacidades, acceso a nuevas tecnologías, oportunidades de aprendizaje, habilidades relacionadas con el trabajo ( $u$ otras actividades), y habilidades funcionales (competencia personal, conducta adaptativa, comunicación).

Bienestar Físico: Tener buena salud, sentirse en forma física, tener hábitos de alimentación saludables. Incluye los indicadores: atención sanitaria, sueño, salud y sus alteraciones, actividades de la vida diaria, acceso a ayudas técnicas y de alimentación.

Autodeterminación:: Decidir por sí mismo y tener oportunidad de elegir las cosas que quiere que sea su vida, su trabajo, su tiempo libre, lugar donde vive, las personas con las que está. Los indicadores con los que se evalúa son: metas y preferencias personales, decisiones, autonomía y elecciones.

Inclusión Social: Ir a lugares de la ciudad o del barrio a donde van otras personas y participar en sus actividades como uno más. Sentirse miembro de la sociedad, sentirse integrado, contar con el apoyo de otras personas. Evaluado por los indicadores: integración, participación, accesibilidad y apoyos.

Derechos: Ser considerado igual que el resto de la gente, que respeten su forma de ser, opiniones, deseos, intimidad, derechos. Los indicadores utilizados para evaluar esta dimensión son: intimidad, respeto, conocimiento y ejercicio de derechos.

\section{Calidad de vida y su relación con el VIH}

Leite et al. (30) sostiene que debido a que los individuos con $\mathrm{VIH}$, están inmersos en un entorno social, se debe considerar la CV. Debido a que, la CV son un conjunto de acciones que permitirán al paciente con VIH una sensación de bienestar al valorar que su integridad no solo depende de lo físico sino también de lo psicológico, social y cultural (31).

Concretamente, la CV relacionada con la salud evalúa la posibilidad de satisfacción con la vida de la persona de forma subjetiva mientras que se hace énfasis en la valoración de aspectos psicosociales y del bienestar percibido por la persona en estado seropositivo. La CV de los pacientes con VIH se puede definir como la percepción y vivencia que tiene el paciente frente a los efectos generados por su condición determinada (32). La CV se asocia a diversas alteraciones psicológicas, entre ellas, la depresión, misma que se desarrolla a continuación.

\section{DEPRESIÓN}

\section{Definición}

Los clínicos definen la depresión en función de una serie de síntomas que forman parte de cuatro grupos(2): 1) síntomas afectivos, tristeza, el mal humor y desánimo);
2) conductuales (aislamiento, reducción de actividades, desinterés y lentitud al hablar o realizar tareas y conducta de escape, entre otras); 3) cognitivos, pensamientos negativos de sí mismo, de otros $y / 0$ acerca del futuro, la baja autoestima, sentimientos de desesperanza y remordimiento; 4) síntomas físicos (falta o exceso de apetito y/o sueño, además de falta de energía; 29).

La depresión es una enfermedad que vulnera el estado de ánimo en general, quien la padece pierde el interés por el mundo y por su propia vida, además de que presenta pensamientos recurrentes de inutilidad y de desesperanza, por lo que deja de ser funcional socialmente, así, los síntomas propios del VIH más los síntomas de la depresión hacen aún más vulnerable física y psicológicamente a los pacientes seropositivos (33).

\section{Etiología de la depresión}

La etiología de la depresión puede tener varios factores, desde orígenes biológicos, fisiológicos, hasta hormonales, algunos pueden ser provocados, como el estrés. Pérez, Cervantes, Hijuelos, Pineda, y Salgado (34) formulan una hipótesis donde se menciona que la depresión es causada por un déficit funcional de los neurotransmisores noradrenalina (NA) y la serotonina $(5-\mathrm{HT})$, en las regiones límbicas (emocionales) del cerebro.

De igual manera, existe una predisposición genética que incorpora genes con efecto aditivo, de tal manera que logra interactuar con diferentes factores externos como la alimentación, eventos estresantes, consumo de sustancias nocivas, entre otras; que de alguna manera aumentan el riesgo de sufrir un episodio depresivo en algún momento de la vida. Como se menciona, los eventos estresantes son un pilar de la cadena de factores externos que logran provocar la depresión, debido a las reacciones corporales; provocando un síndrome de adaptación general donde el organismo hace todo el esfuerzo necesario para poder adaptarse a las nuevas condiciones de vida. Cabe señalar que el estrés es un proceso normal, se da para poder mantener un equilibrio y la estabilidad de respuestas corporales, sin embargo, a largo plazo y de forma activa puede incrementar el riesgo de dicho padecimiento (34).

\section{Cuadro clínico/síntomas}

Para un diagnóstico acertado es importante identificar una serie de signos y síntomas que son propios de la depresión. El estado de ánimo en la mayoría se ve alterado de forma grave, ya que las personas que lo padecen suelen estar irritables. Pero, se pueden presentar altibajos del estado de ánimo a lo largo del día, la presencia de llanto es frecuente al recordar experiencias pasadas, presentes y sobre el futuro, principalmente son negativas. Por ejemplo, los sentimientos de culpa son-recurrentes, ya sea por cosas que hizo o dejó de hacer en algún momento de su vida, 
el sujeto piensa que a través de la enfermedad está expiando sus culpas y que merece sentirse así. Existe pérdida de interés en actividades que anteriormente eran placenteras y dificultad para mantener o hacer amistades (35).

Es frecuente que el paciente tenga pensamientos suicidas. Constantemente se observa una disminución de energía, ya que presentan dificultades para conservarse aliñados, por realizar actividades básicas como bañarse, tareas del hogar, cocinar, etc. Además, disminuye el apetito, por lo que el peso corporal se ve afectado y también, disminuye el deseo sexual (33).

\section{Factores de protección}

Existen diversos factores protectores contra la sintomatología de depresión, que no sólo aplican para los pacientes con VIH sino para la población en general. Si bien, es cierto que las situaciones estresantes de la vida cotidiana aumentan la probabilidad de padecer depresión u otro trastorno de ánimo, por tanto, el apoyo social o red social es un factor de protección, que permite el ajuste psicosocial hacia la enfermedad, en esta red social se incluye a la familia, amigos y compañeros de trabajo, de la misma institución de salud donde son atendidos. Se ha sugerido que, el apoyo social se puede dar en tres vías: a) por integración social; b) percibido (cuando dicho apoyo se requiere); c) el provisto que es cuando otros, ya sea familiares o profesionales de la salud proveen su asistencia (36). Existen evidencias de que pacientes con $\mathrm{VIH}$ con adecuadas red de apoyo mantienen un mayor equilibrio en su salud, comparados con quienes carecen de dicha red. Se ha sugerido que es necesario promover grupos de apoyo dirigidos a instituciones de salud con el objetivo de promover estrategias para enfrentar las consecuencias del VIH (37).

\section{Factores}

de

riesgo

Sarason y Sarason en 2006 (34) sostienen que de manera general, existen distintas circunstancias 0 situaciones que aumentan la probabilidad de sufrir depresión. Así, la herencia juega un papel fundamental, ya que, si algún familiar cercano ha padecido algún trastorno del estado de ánimo, existirá mayor posibilidad de que el familiar pueda padecerlo. Otros factores de riesgo comunes son: ser mujer y tener entre 20 y 29 , ser hombre y tener entre 40 y 49 años, acumular eventos estresores en poco tiempo y la falta de apoyo en las redes primarias. Algunos otros factores que aumentan la probabilidad de padecer depresión son: el divorcio, ser parte de la clase baja, la inestabilidad laboral, ser parte de alguna comunidad, problemas en el ámbito laboral y/o familiar (38).

En los pacientes con VIH, son múltiples los factores que propician el riesgo de padecer depresión, por ejemplo, el mismo diagnóstico, perder a la pareja, a la familia, despido laboral, carencia económica para atender la enfermedad, el estigma social, cambios en la apariencia física, entre muchos otros más.

\section{Tratamiento}

Existen dos alternativas de tratamiento para la depresión; la primera es un tratamiento biológico con compuestos químicos que modifican la labor de los neurotransmisores dentro de la actividad cerebral, a través de medicamentos antidepresivos como lo son los inhibidores de la monoaminooxidasa, antidepresivos tricíclicos y los inhibidores selectivos de la reabsorción de serotonina; de igual manera existe la terapia electroconvulsiva: este método se utiliza en grados más severos de depresión o cuando los antidepresivos no están actuando de manera rápida. La terapia consiste en pasar una breve corriente de electricidad por la cabeza, pero por la misma naturaleza de la enfermedad, no es adecuado su uso (34).

El tratamiento biológico, en especial los medicamento antidepresivos se prescribirá dependiendo del cuadro clínico del paciente y a las reacciones adversas que se tengan, por consiguiente uno de los problemas que se tiene con este método es que dependiendo de estas reacciones el medicamento tiene una respuesta terapéutica de entre 2-4 semanas en aparecer, y de 4-6 semanas para conseguir un pleno efecto. De igual manera los antidepresivos no modifican el estado del ánimo en los individuos, su objetivo es suprimir las ideas o sentimientos depresivos (39).

La segunda vía es el tratamiento psicológico, donde la psicoterapia es útil para tratar la depresión y es un coadyuvante importante para él el tratamiento biológico; existen diferentes perspectivas de la psicoterapia en donde cada una de ellas ocupa un método diferente para atender este padecimiento como por ejemplo, la psicoterapia interpersonal, humanista-existencial, conductual cognitiva, cognitivo-conductual, entre otras, (40).

El tratamiento conductual se basa en la disminución de la conducta a través de reforzadores positivos o de inadecuaciones de habilidades sociales; existen 3 tratamientos conductuales como lo son: 1) Programa de Actividades Agradables; donde se pretende modificar la cantidad y la calidad de las interacciones del paciente depresivo mediante estrategias de relajación, toma de decisiones, solución de problemas, manejo del tiempo y entrenamiento asertivo, 2) Entrenamiento en Habilidades Sociales; este tratamiento está orientado a mejorar la aserción negativa (conductas que permiten a la persona defender sus derechos y actuar de acuerdo con sus intereses), la aserción positiva (expresión de sentimientos positivos hacia otros) y las habilidades conversacionales, y 3) Curso para el Afrontamiento de la Depresión; esta terapia se concibe como un tratamiento psico-educativo donde existe un instructor o líder y un participante en curso, se desarrollan actividades agradables, entrenamiento de habilidades sociales y la modificación de cogniciones

(28) 
Terapia cognitiva; este modelo se basa en aquellas interpretaciones erróneas de acontecimientos y de situaciones se deben afrontar día a día, dejando así un aprendizaje o formando ciertos esquemas de creencias que tiene por consecuencias emociones y comportamientos negativos. Es por ello que las técnicas utilizadas son: pensamientos racionales, plan de actividades agradables, cambiar pensamientos, colaboración, tareas para casa y una nueva estructuración de la terapia (41).

Por otro lado, la Terapia Cognitivo-Conductual se caracteriza por trabajar con técnicas que han sido diseñadas y estructuradas para lograr identificar y modificar aquellos pensamientos y actitudes negativas que involucran la percepción de uno mismo, de su entorno y de su futuro (42)

La terapia interpersonal a diferencia de las otras anteriormente señaladas no se centra en la depresión sino en las relaciones interpersonales del sujeto, se dice que las malas relaciones que tiene el sujeto con su entorno (los roles en la sociedad) provocan un estado de estrés que por consiguiente inducen un estado depresivo; la psicoterapia interpersonal tiene como objetivo desarrollar aquellas herramientas necesarias para poder desenvolverse en los diferentes ámbitos de su vida, todo esto es a través de las siguientes técnicas; exploración de los roles y relaciones sociales, aceptación y manejo de emociones, clarificar el estado de la comunicación entre otras (39).

Se puntualiza que la terapia que ha brindado mejores resultados es la terapia cognitivo-conductual

\section{Depresión y su relación con el VIH}

Cuando las personas son diagnosticadas con VIH y los familiares son notificados; ambas vivencias tienden a inclinarse a pensamientos trágicos por medio de las experiencias dentro de su entorno cultural, es por ello que, normalmente se tiende a asociar el VIH con la muerte, el miedo al contagio, la desviación moral y el rechazo social (43).

Existe una prevalencia importante de depresión en pacientes con $\mathrm{VIH}$, relacionada con las implicaciones sociales que puede traer consigo dicha enfermedad (aislamiento, pérdida de empleo, rechazo familiar, etcétera), además de los deterioros que trae consigo la enfermedad, como ya se mencionó con anterioridad (44).

La depresión se ha considerado como una causa de la morbilidad y de mortalidad en pacientes con $\mathrm{VIH}$, debido a que los estados depresivos afectan en la CV ya que, interfiere en la adherencia al tratamiento, aumenta el dolor, desregula el sistema inmunológico, disminuye el soporte social, interfiere en las relaciones interpersonales y disminuye la productividad de las personas, por lo que es claro que la presencia de depresión entre los pacientes con VIH potencializa el riesgo para la salud (45).

La prevalencia de la depresión en personas seropositivas es de un $37 \%$ en comparación con la población en general; esta cifra aumenta hasta el triple y con más frecuencia en mujeres y adolescentes, personas con menor nivel de educación, los que tienen inestabilidad económica y laboral, los que tienen menos creencias religiosas, así como los pacientes con malas redes de apoyo. Pero es importante destacar que esta prevalencia puede estar sub representadas debido a que, los médicos no revisan el cuadro clínico que presenta el paciente y también por aquella omisión que existe del paciente al no mencionar su estado emocional (46), porque se cree que es parte natural de la enfermedad.

Pero existe otro factor psicológico que afecta a los pacientes con $\mathrm{VIH}$, se trata de la ansiedad que las personas pueden presentar en el proceso de su condición.

\section{ANSIEDAD}

\section{Definición}

La ansiedad es uno de los conceptos más estudiados y de mayor relevancia para la psicología, ante ello, esta disciplina no se ha dejado limitar a investigaciones propias a una conducta anormal sino que, se extienden a personas que se le consideran normales, visibilizando que ningún humano está exento de experimentar este estado emocional o sensación (47). Otra definición importante, la entiende como un sentimiento de miedo y aprensión, difuso, vago y muy desagradable en donde la persona ansiosa se preocupa excesivamente, sobre todo por aquello que es desconocido y que presenta un nivel de molestia para la persona (48).

De acuerdo con el Ministerio de Sanidad y Consumo (49) la ansiedad puede conceptualizarse como una anticipación sobre algún daño o desgracia futuros acompañada de un sentimiento de disforia (desagradable) y/o de síntomas somáticos de tensión. Es importante entender a la ansiedad como una sensación o un estado emocional normal, inclusive, es deseable para lograr un empleo favorable en las exigencias del día a día. Sin olvidar que si se sobrepasa cierto grado de intensidad, supera la capacidad adaptativa de la persona 0 su duración es injustificadamente extensa y la recurrencia es inmotivada, en estas situaciones, la ansiedad se convierte en patológica, provocando así, un malestar relevante con síntomas específicos que no solo afectan el plano físico, si no también tiene impacto a nivel psicológico y conductual, añadiendo a este lo interpersonal.

La ansiedad generalmente, tiene un sinfín de diversas definiciones que convergen entre sí, oscilando desde la 
perspectiva de ser un sentimiento, un síndrome o un síntoma. Tomando el concepto de ansiedad desde la idea que es un sentimiento se entiende como una sensación normal de tensión provocada por estímulos internos como recuerdos, pensamientos, problemas o fantasías. Desde la perspectiva "ansiedad como síntoma" forma parte de cualquier enfermedad psiquiátrica y constituye el componente psicológico esencial de los trastornos de ansiedad. Viéndola como un síndrome es el conjunto de síntomas psiquiátricos, físicos y conductuales, regidos por mecanismos neurobiológicos. Puede ser secundario a una intoxicación, abuso, abstinencia o efecto de sustancias, $y$, por último, ansiedad como enfermedad es referida al cuadro clínico ansioso definido, tiene su propia etiopatogenia, evolución, pronóstico y tratamiento (50).

\section{Cuadro}

clínico/Síntomas

De acuerdo con American Psychiatric Association (51) entre los principales síntomas que se pueden presentar se encuentra: ritmo cardíaco acelerado, respiración entrecortada, diarrea, pérdida del apetito, desmayos, mareos, sudoración, insomnio y estreñimientos. Esta sintomatología es compartida con el miedo; la diferencia entre el miedo y la ansiedad es que en el primero para la persona es fácil identificar y divulgar qué es el objeto a lo que le temen mientras que, por otro lado, en la segunda no están conscientes de cuál es la causa de sus temores.

En casos graves las personas que sufren de Trastornos de Ansiedad (TA), a menudo los pensamientos intrusivos toman forma sobre los acontecimientos y consecuencias futuras probables 0 interpretaciones catastróficas de acontecimientos pasados que destacan lo negativo, en especial los errores que el individuo pudo haber cometido. Estos pensamientos son características de una experiencia de ansiedad, que puede tener un carácter automático creado por el individuo (34). En la tabla 1 se aprecian los síntomas principales de la ansiedad a nivel somático, psicológico y conductuales.

Tabla 1

Síntomas de ansiedad comunes

\begin{tabular}{|c|c|}
\hline Somáticos & Psicológicos y conductuales \\
\hline Sudoración & Preocupación, aprensión \\
\hline Mareos & Sensación de cansancio \\
\hline Temblores & $\begin{array}{l}\text { Miedo de perder el control, a volverse loco o } \\
\text { sensación de muerte inminente }\end{array}$ \\
\hline Tensión muscular & Dificultad de concentración \\
\hline \multicolumn{2}{|c|}{ Palpitaciones/Taquicardias Quejas de pérdida de memoria } \\
\hline Náuseas & Irritabilidad, inquietud, desasosiego \\
\hline Vómitos & Conductas de evitación \\
\hline Estreñimiento & Obsesiones o compulsiones \\
\hline Diarrea & Insomnio \\
\hline Micción frecuente & Hipervigilancia \\
\hline
\end{tabular}

\section{Etiología de la ansiedad}

Dentro de las causas que engloban la ansiedad existen factores biológicos, sociales, psicodinámicos entre otros, sin embargo, el factor neurobiológico consta con una hipótesis representativa sobre cómo es generada la ansiedad, de acuerdo con esto tiene una base en zonas del tallo cerebral que se involucran con el desarrollo y la transmisión de la angustia a través del hipocampo y la amígdala que se encuentran en el sistema límbico, junto con este factor se encuentra el factor genético debido a que existen agentes predisponentes a un TA. Los factores sociales son aquellos estresores como los aspectos económicos, laborales, interpersonales; de igual manera los factores traumáticos como los son accidentes, desastres naturales, violaciones etc. pueden provocar daños biológicos que influyen en la ansiedad (52).

\section{Factores de protección}

La ansiedad así como otras condiciones mentales tienden a tener factores de protección que ayudan a la posible disminución, control y tratamiento del trastorno. Algunos de ellos y los más denotativos, se encuentran en las redes de apoyo que la persona puede llegar a tener, puesto que suponen de una motivación hacia la persona con TA para lograr una adherencia al tratamiento ya sea psicológico o farmacológico sino, es que la combinación de ambos, logrando una disminución de factores estresores que puedan estar entorno a la persona. (53).

\section{Factores de riesgo}

La Secretaría de Salud (54) identifica estresores biológicos, ambientales y psicosociales que pueden ser provenientes de aquellas dificultades con el grupo primario referente al ambiente social como lo es la familia, lo educativo, legal, laboral; que por consecuencia suelen tener mayor riesgo de conductas suicidas.

Los factores biológicos están enfocados en alteraciones neurobiológicas como lo son fallas en los neurotransmisores, en las bases neuroendocrinas, anomalías estructurales en el sistema límbico y la base psicofisiológica. Por otro lado los factores psicológicos se fundamentan más en los procesos de aprendizaje, en las características de personalidad, en el déficit de habilidades sociales y en los procesos cognitivos (estructuras y estrategias del procesamiento de la información). En cuanto a los factores socioculturales se presentan los valores existentes en diferentes culturas, la interacción social, las relaciones interpersonales, los juicios sobre la propia persona, los eventos estresantes y/o traumáticos, la historia familiar, el consumo de sustancias y preocupaciones, entre otros (55).

\section{Tratamiento}

De acuerdo con el Instituto Nacional de Salud Mental (56) los TA pueden ser tratados con medicación, diferentes tipos de psicoterapia o una implementación de ambos. La elección del modo para una mejor vía de intervención va a ser decidida principalmente basándose 
en la persona y al tipo de TA que presente, habiendo la posibilidad de coexistencia con otros trastornos que deben ser diagnosticados oportunamente.

Ya sea un tratamiento farmacológico o psicoterapéutico la principal finalidad de ambos es lograr un alivio de los síntomas que presenta la persona, evitar las secuelas y ayudar en la resolución de los problemas psicosociales que los TA pueden causar al igual que estar en una constante búsqueda de la efectividad en términos de coste/beneficio (46).

El tratamiento basado en la medicación no suele ofrecer una cura real para los TA o su sintomatología, su función es mantenerlos bajo control, estos deben ser prescritos por un profesional de la salud, como lo son los psiquiatras .Los principales fármacos implementados son los antidepresivos, medicamentos ansiolíticos (pastillas específicas para tratar ansiedad/nervios) y bloqueadores beta con la finalidad de controlar algunos síntomas físicos. En cambio, la terapia psicológica ofrece otra alternativa de solución a los TA o su sintomatología, este tipo de tratamiento es proporcionado por profesionales de la salud como terapeutas, trabajadores sociales o psiquiatras, pero los indicados deben ser los psicólogos (57).

Como lo mencionan Sarason y Sarason (34) el hablar sobre tratamientos de los TA puede crear una serie de conflictos, puesto que se pueden presentar síntomas similares en los diferentes tipos de trastornos de ansiedad y no requieren las mismas formas de intervención, ya que el emplear el mismo tratamiento para todos puede desembocar una ineficacia a la hora de darles una resolución positiva. Por ello se ha logrado a través del tiempo tener un abanico de posibles formas de abordaje basándose en una diversidad de perspectivas teóricas.

De acuerdo con la perspectiva psicodinámica existe gran diversidad de etiologías para los TA, que van desde el sentimiento de la inutilidad e incapacidad de enfrentar situaciones de la vida, miedo al abandono o pérdida del amor, del apoyo emocional hasta impulsos inaceptables. Los terapeutas con este enfoque buscan que el paciente se vuelva consciente y encuentre la raíz de aquello que le genera ansiedad (34).

La perspectiva cognitivo-conductual suele ser eficaz para los TA, en la parte cognitiva ayuda a cambiar los patrones del pensamiento que dan pauta a sus temores percibidos y por la parte conductual ayuda a cambiar las reacciones que las personas suelen tener ante las situaciones que les provoca la ansiedad. Una de las técnicas más utilizadas por los terapeutas con este enfoque se basa en la exposición o en la reestructuración cognitiva. Dichas técnicas se pueden llevar a cabo individual o grupalmente (58).
Ansiedad y su relación con el VIH Los pacientes diagnosticados seropositivos enfrentan una serie de situaciones estresantes de índole sociocultural, económica y psicológica, añadiendo las propias de su condición actual, logrando así, una incrementación de su vulnerabilidad ante el $\mathrm{VIH}$, teniendo posiblemente un impacto más negativo a su salud. Existen evidencias de que pacientes con VIH presentan síntomas de ansiedad de moderados a graves, pero se comporta de manera diferencial, ya que, un porcentaje mayor de afectadas son las mujeres y con mayores niveles de gravedad, esto puede deberse al factor cultural, por los roles de género, los estereotipos y la falta de educación en temas de autocuidado y sexualidad, ya que, la presencia de VIH en la mujer se le atribuye a infidelidad, mientras que a los hombres por descuido (58). Además, se ha referido que existe el doble de probabilidad de padecer ansiedad entre los pacientes con VIH en comparación con personas sin el virus (59)

Lambán et al. (60) concluyeron que sobre la incidencia entre la sintomatología de ansiedad y depresión, considerando que es importante realizar un cribado de los síntomas psiquiátricos de igual manera para lograr un mejor manejo y calidad de vida del paciente con VIH basándose en los resultados finales de dicha investigación haciendo hincapié que la ansiedad es presentada en su mayoría con población de mujeres que de hombres.

\section{Consideraciones finales}

Sin duda, el papel de los médicos en el VIH es punto clave para garantizar la salud física de quien es portador, sin embargo, el papel del psicólogo es relevante para coadyuvar en la salud integral de esta población. Los psicólogos de la salud, son los indicados para comprender y atender los pensamientos, las percepciones, creencias, ideas, actitudes y comportamientos no saludables que pueden experimentar las personas a lo largo de un proceso salud-enfermedad, ya sea a nivel primario, secundario o terciario, debido a los efectos negativos a nivel individual y social.

Así, es necesario fortalecer y reconocer el papel del psicólogo de la salud en el proceso de una enfermedad, más cuando se trata de un virus que afecta a una porcentaje importante de personas no sólo a nivel mundial y nacional, sino también a nivel estatal. En virtud de que los factores de riesgo -en mayor medidason conductas poco saludables, se puede psicoeducar preventivamente y reducir los casos nuevos o aminorar los efectos del impacto inicial de dicha enfermedad, o en el proceso del tratamiento.

Al respecto, el papel del psicólogo de la salud debe ser parte imperante del equipo interdisciplinario de profesionales de la salud, porque hay evidencias de que alteraciones como la sintomatología de ansiedad, de 
depresión o una mala CV, complejizan el curso natural de la enfermedad, acortando la esperanza de vida.

El papel de la familia y sociedad en general juegan un papel fundamental para preservar la salud física y psicológica, así otra aportación del papel del psicólogo es la salud es sensibilizar a la población sobre la discriminación y mitos alrededor del VIH, por contrario debe promover el fortalecimiento de las redes de apoyo, para mejorar la CV, disminuir la sintomatología de ansiedad y depresión, ya que, estas vuelven más vulnerable a las personas en estado seropositivo.

La psicología como disciplina científica se encarga de formar a profesionales competentes para atender las demandas del medio ambiente, en tanto que la función de psicología de la salud es la promoción de la salud y la prevención de la enfermedad, principalmente a través de la modificación del comportamiento humano, lo cual, es importante a la hora de realizar evaluación del estado de la salud psicológica de manera oportuna, así como crear programas de intervenciones ad hoc a la población con VIH y a la sociedad en general, ayudando así a los pacientes a desarrollar ciertas herramientas necesarias; modificar su estilo de vida y garantizar el bienestar del paciente y sus allegados.

El presente ensayo corresponde a la mirada desde la psicología, pero es una realidad que un trabajo interdisciplinario permitirá un comprensión más amplia entre los mismos profesionales de la salud, como pueden ser médicos, enfermeras, nutriólogos, etc. El presente ensayo se centró en la CV, sintomatología de ansiedad y de depresión, por lo que futuros estudios podrán abordar otras variables relacionadas a los pacientes con VIH.

\section{Referencias}

1. Codina C, Martín MT, \& Ibarra O. La infección por el virus de la inmunodeficiencia humana. Farmacia Hospitalaria Tomo II Madrid: Sociedad Española de Farmacia Hospitalaria; 2002:1493-1516.

2. Centro Nacional para la Prevención y el Control del $\mathrm{VIH} / \mathrm{SIDA}$. Informe nacional de avances en respuesta al VIH/SIDA [Internet]. México: CENSIDA; 2015. [Consultado el 28 de mayo de 2019]. Disponible en: http://www.censida.salud.gob.mx/descargas/ungass/GARPR M×20 $\underline{15 . p d f}$

3. Arístegui I, Pemoff R, Flighelman M, Warth S, Vergani $F$, Zalazar V, \& Mercado A. Abordaje psicológico de personas con VIH: Sistematización de la experiencia de atención psicosocial de Fundación Huésped [Internet]. Buenos Aires: Fundación Huésped; 2012 [Revisado el 28 de mayo de 2019]. Disponible en: https://www.huesped.org.ar/wp-content/uploads/2014/11/Abordajepsicologico-de-personas-con-VIH.pdf

4. Mendoza AM, Ferrando R, Álvarez T, Pascual MO, Livana C, Raga $C$ et al. Adherencia al tratamiento antirretroviral en pacientes VIH: todavía queda mucho por hacer. OFILILAPHAR. 2018;28(3):203-210.

5. Pérez J, Respuestas emocionales, enfermedad crónica y familia. En: Enrique Fernández \& Francesc Palmero Eds. Emociones y Salud. Barcelona: Ariel;1999
6. Organización Mundial de la Salud. VIH/SIDA [Internet]. OMS. 2019. [citado 28 de mayo de 2019]. Recuperado a partir de: https://www.who.int/es/news-room/fact-sheets/detail/hiv-aids

7. Factográfico de la Salud. VIH/SIDA Estadísticas Mundiales [Internet]. Biblioteca Médica Nacional. 2018. [citado 28 de mayo de 2019]. Recuperado a partir de: http://files.sld.cu/bmn/files/2018/02/factografico-de-salud-febrero2018.pdf

8. Centro Nacional para la Prevención y el Control del VIH/SIDA. La epidemia del VIH y Sida en México [Internet]. México: CENSIDA; 2015. [Consultado el 28 de mayo de 2019]. Recuperado a partir de de: http://www.censida.salud.gob.mx/descargas/principal/la epidemia deVIHysidaMexico.pdf.

9. Secretaría de Salud. Guía de manejo antirretroviral de las personas con VIH. 6ta. ed. México: Censida; 2014. 164.

10. Elizondo S, Concentra [s.f] Pachuca 54\% de casos de VIH. México: Criterio.[internet].[5 de agosto 2018]. Recuperado de https://www.criteriohidalgo.com/noticias/hidalgo/concentrapachuca-54-de-casos-de-vih

11. Rubiano $\mathrm{Y}$, \& Saldarriaga J, Jóvenes y VIH/SIDA: enfoques y perspectivas en investigación. Index de Enfermería. $2011 ; 20: 1-2$

12. García M, Rio A, Sepúlveda J, Valdespino J, Velázquez $L$, \& Volkow $\mathrm{P}$, La estrategia de prevención de la transmisión del $\mathrm{VIH} / \mathrm{SIDA}$ a través de la sangre y sus derivados en México. Instituto Nacional de Salud Pública México.1995; 37(6):624-635.

13. Sánchez C, Acevedo J, \& González M. (2012). Factores de riesgo y métodos de transmisión de la infección por el virus de la inmunodeficiencia humana. Revista CES Salud Pública. 2012;1(3);28-37.

14. Sopeña B. Trastorno vertical del VIH-1. SeNicio de Medicina Interna-Unidad de Enfermedades Infecciosas. Complejo Hospitalario Xeral-Cíes de Vigo.1997; 2:831-837.

15. Lamotte-Castillo J. Infección por VIH/sida en el mundo actual. MEDISAN. 2014;18(7):117-138.

16. Grupo de expertos del Grupo de Estudio de SIDA (GeSIDA) y de la Secretaría del Plan Nacional sobre el Sida (SPNS). Documento de consenso sobre el manejo clínico de los trastornos neurocognitivos asociados a la infección por el virus de la inmunodeficiencia humana. Enfermedades Infecciosas y Microbiología Clínica. 2013; 32(1):37-47.

17. Lozano F. Alteraciones morfológicas (I): Etiopatogenia y clínica. En: Muñoz A, editor. Efectos adversos del tratamiento antirretrovírico. Barcelona: Lippincott Williams \& Wilkin; 2007. 89100.

18. Piña J, Robles S. Psicología y VIH/SIDA en México: su prevención con base en un modelo psicológico de salud biológica. Revista de Psicopatología y Psicología Clínica. 2005;10(1):71-83. 
19. Ospina-Sigfredo S. Diagnóstico de la Infección por el Virus de la Inmunodeficiencia Humana. Asociación Colombiana de Infectología. 2006;10(4):237-278.

20. Lamotte-Castillo J. Diagnóstico rápido de la infección por $\mathrm{VIH} /$ sida. MEDISAN. 2014;18(3):299-301.

21. Ballester $\mathrm{R}$, Aportaciones desde la psicología al tratamiento de las personas con infección por VIH/SIDA. Revista de Psicología y Psicología Clínica. 2005; 10(1):53-69.

22. Moreno B, \& Ximénez C. Evaluación de la calidad de vida. (Eds.). En G. Buela, V. Caballo \& C. Sierra. Manual de evaluación en psicología clínica y de la salud. Madrid: Siglo XXI; 1996. p. $1045-1070$.

23. Urzúa A, \& Caqueo A. Calidad de Vida: Una revisión teórica del concepto. Terapia Psicológica. 2012; 30(1):61-71.

24. Organización Mundial de la Salud. Report of the WHOQOL focus group work. 1995. Recuperado de www.who.int/mental_health/media/68.pdf

25. Nava M, La calidad de vida: Análisis multidimensional. Revista de Enfermería Neurológica. 2012; 11(3):129-137.

26. Robles A, Rubio B, De la Rosa V \& Nava A Generalidades y conceptos de calidad de vida en relación con los cuidados de salud. El Residente. 2016; 11(3):120-125.

27. Mondragón A. ¿Qué son los indicadores?. Revista de Información y Análisis. 2002; 1(19):52-58.

28. Schalock R, Verdugo M, Arias B, Gómez L \& Urríes B. Calidad de vida. Discapacidad e inclusión: Manual para la docencia. Salamanca: Amerú; 2013.

29. Leite R, Oliveira, D, Costa T, Correa S, Ramos E \& Tosoli A. Calidad de vida de personas conviviendo con HIV/SIDA: relación temporal, sociodemográfica y perceptiva de la salud. Revista Latino Americana de Enfermagem. 2017;25:1-10.

30. Frutos C, Aquino N, Amado D, Ferreira M \& Díaz C. Calidad de vida en el Paciente con VIH en el servicio de Clínica Médica, Hospital central-Instituto de Previsión social Paraguay2015. Revista Médica del Instituto Mexicano del Seguro Social. 2015; 11(1):10-21.

31. Pérez M \& García JM. Tratamientos psicológicos eficaces para la depresión. Psicothema. 2001;13(3): 439-510.

32. Baena A, Sandoval M A, Urbina CC, Juárez, NH \& Villaseñor SJ. Los trastornos del estado de ánimo. Revista Digital Universitaria. 2005;6(11):2-14.

33. Sarason I. \& Sarason R. Psicopatología, Psicología anormal: el problema de la conducta inadaptada. México: Pearson; 2006. 702.

34. Riveros M, Hernández $H$ \& Rivera J. Niveles de depresión y ansiedad en estudiantes universitarios de Lima Metropolitana. Revista IIPSI. 2007; 10(1): 91-102.
35. Pérez E, Cervantes V, Hijuelos N, Pineda J \& Salgado H. Prevalencia, causas y tratamiento de la depresión mayor. Revista Biomédica. 2017;28(2):89-115.

36. Mosqueda DE, Reyes GC, Montuy Y, Miranda A \& Arcos KC. Apoyo social en personas que viven con VIH. Salud Educación, Sociedad y Economía en la Frontera Sur de México. 2017. Recuperado de http://www.sidastudi.org/resources/inmagicimg/DD46905.pdf

37. Sequeira A \& Fornaguera J. Neurobiología de la depresión. Revista Mexicana de Neurociencias. 2009;10(6):462478.

38. Raffaelli M, Andrade F, Wiley A, Sanchez O, Edwards L $L \&$ Aradillas $C$. Stress, social support, and depression: $A$ test of the stressbuffering hypothesis in a Mexican sample. Journal Research Adolescence. 2013; 23:283-289.

39. Lillo JL. Crecimiento y comportamiento en la adolescencia. Revista de la Asociación Española De Neuropsiquiatría. 2004; 40:57-71.

40. Rosenfarb I, Miklowitz D, Goldstein M, Harmon L, Nuechterlein KH \& Rea MM. Family transactions and relapse in bipolar disorder. Family Process. 2001; 40(1):5-14.

41. Díaz LJ. Torres V, Urrutia E, Moreno R., Font I \& Cardona M. Factores psicosociales de la depresión. Revista Cubana de Medicina. 2006; 35(3):1-7.

42. Quintana E. El papel de enfermería en la depresión mayor. Tesis doctoral. Universidad de Cantabria España; 2017.

43. Perello M., Martínez C \& Llorens N. Eficacia y efectividad de los tratamientos psicológicos para la depresión. Información Psicológica. 2001; 76:43-49.

44. Solano N., Gallagher D. Intervenciones cognitivoconductuales para la depresion en personas mayores. La eficiencia de la terapia cognitivo-conductual para el tratamiento de la depresión en personas mayores. Revista Española de Geriatría y Gerontología. 2001;36(4):189-194.

45. Almanza, A \& Flores, F. Resistencia a la discriminación: narrativas familiares acerca de la infección por VIH. Un estudio exploratorio. Psicología y Salud. 2012; 22(2):173-184.

46. American Psychiatric Association. Manual Diagnóstico y Estadístico de los trastornos mentales. 5ta ed. Washington DC: American Psychiatric Publishing, 2013. 947 p.

47. Galindo, J \& Ortega M. Prevalencia de depresión en pacientes con VIH/SIDA en el Hospital General de Zona \# 11 del Instituto Mexicano del Seguro Social (IMSS), Lic. Ignacio Díaz Téllez. Enfermedades Infecciosas y Microbiología.2010; 30(4):129133.

48. Reis R, Hass, V, Benedita, C, Araujo, S, Gimenez M. \& Gir E. Síntomas de depresión y calidad de vida de personas viviendo con HIV/Sida. Revista latino Americana Enfermagem. $2011 ; 19(4): 1-8$

49. Wolf C, Alvarado R. \& Wolf M. Prevalencia, factores de riesgo y manejo de la depresión en pacientes con infección por VIH: Revisión de literatura. Revista Chilena de Infectología. 2010;27(1):65-74 
50.

Davison G. \& Neale J. Psicología de la conducta anormal. 2da ed. México: Limusa Wiley. 2002. 863.

51. Ministerio de Sanidad y Consumo. Guía de Práctica Clínica para el Manejo de Pacientes con Trastornos de Ansiedad en Atención Primaria [Internet]. 2008. [revisado 2008, citado en 2019 Agosto 19] Recuperado a partir de https://bit.ly/2jOP5d2

52. Reyes-Ticas J. Trastornos de Ansiedad Guía Practica para Diagnóstico y Tratamiento [Internet]. sf. [revisado sf, citado en 2019 Agosto 21] Recuperado a partir de: https://bit.ly/2cXHSq4

53. American Psychiatric Association. Guía de consulta de los criterios de diagnósticos del DSM-5. Arlington, VA: American Psychiatric Publishing; 2013. 492.

54. Nava W \& Vargas M. Trastornos de ansiedad: revisión dirigida para atención primaria. Revista Médica de Costa Rica y Centroamérica. 2012;69(604):497-507.

55. Secretaría de Salud. Guía de práctica clínica diagnóstico y tratamiento de los trastornos de ansiedad en el adulto. México: Cenetec: 2010

56. Sierra J, Zubeidat I \& Fernández A. Factores asociados a la ansiedad y fobia social. Revista Mal Estar e Subjetividad e. 2006;6(2):472-517.

57. Berg C, Michelson SE, Safren SA. Behavioral aspects of HIV care: Adherence, depression, substance use, and HIV Transmission behaviors. Infect Dis Clin N Am 2007; 21: 181-200.

58. Instituto Nacional de Salud Mental. Trastornos de ansiedad. [Internet].Estados Unidos: Instituto Nacional de Salud Mental, 2009. [revisado 2009, citado en 2019 Agosto 21] Recuperado a partir de: https://bit.ly/2OpuBnH

59. Arrivillaga M, Correa D, Holguín L \& Tovar J. Variables psicológicas en mujeres diagnosticadas con $\mathrm{VIH} /$ sida: un estudio correlacional. University Psychology Bogotá. 2006;5(3): 659-667.

60. Lambán E, Martínez E, López C, Bolea L, Moreno J \& Artajona E. ¿Es importante valorar los síntomas de Ansiedad y Depresión en población VIH?. Revista Multidisciplinar del SIDA. 2015;1(4): 52-55. 